\title{
Eficiência do nitrogênio e divergência genética em milho visando à produção de proteína
}

\section{Efficiency of nitrogen and genetic divergence in corn aiming for the production of protein}

1,* (D) Weder Ferreira dos SANTOS, 2, (iD Flávio Sérgio AFFÉRRI, 1, (iD Joênes Mucci PELÚZIO, 1,(iD Layanni Ferreira SODRÉ, 1, (iD Evandro REINA e ${ }^{1,(D)}$ Jefferson Da Silva PEREIRA

\author{
${ }^{1}$ Universidade Federal do Tocantins, Campus Gurupi. Rua Badejós, Lote 7, Chácaras 69/72, Zona Rural. CEP: 77402-970. Gurupi-TO, \\ Brasil. \\ 2 Universidade Federal de São Carlos (UFSCar), Centro de ciências naturais. Fazenda Lagoa do Sino Aracaçu CEP 18.295-990, Buri-SP, \\ Brasil.
}

*Autor para correspondência: eng.agricola.weder@gmail.com

\section{RESUMO}

OPPEN ACESS

\section{Informações adicionais}

Recebido em: 14/03/2017

Aceito em: 01/10/2017

Publicado em: 11/12/2017

Editor:

Victor Hugo Gomes Sales Federal Institute of Amapá Macapá, AP.

\section{Revisão às cegas por pares}

Processos de revisão

Prot. 1912017R01 (Brasil)

Prot. 1912017R03 (Brasil)

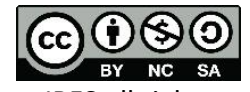

JBFS all rights

Copyright: (C) 2017
A diversidade genética de populações de milho (Zea mays L.), aliado a eficiência e uso de nutrientes, permite a identificação das populações que poderão ser utilizadas como progenitores em futuros programas de melhoramento. Neste sentido, foram realizados quatro ensaios de competição de populações de milho no Centro Agrotecnológico da Universidade Federal do Tocantins, Campus de Palmas, no ano de 2010, sendo dois ensaios na safra e dois na entressafra, sob condições de alto nitrogênio (N) (150 kg ha-1 de $\mathrm{N}$ ) e baixo $\mathrm{N}$ ( $0 \mathrm{~kg}$ ha-1 de $\mathrm{N}$ ) em cobertura. O delineamento experimental utilizado em cada ensaio foi de blocos casualizados com três repetições e 10 tratamentos. Foi determinada a eficiência do uso de nitrogênio (EUN) através da metodologia de Fischer e a divergência genética pelo método de agrupamento de otimização de Tocher, para o teor de proteína dos grãos. No estudo da divergência genética, cada ensaio representou uma variável distinta no modelo multivariado. O menor teor de proteína foi obtido sob baixo $\mathrm{N}$ na safra. As populações POP 3 e POP 13 são eficientes e promissoras para produção de proteínas.

Palavras-chave: Adubação nitrogenada. Conteúdo proteico. Melhoramento genético.

\section{ABSTRACT}

The genetic diversity of maize populations, coupled with the efficiency and use of nutrients, allows the identification of populations that may be used as parents in future breeding programs. Thus, were realized four trials of maize populations in the year 2010, be two installate in inter-crop period and two crops period, in Center Agrotechnological University Federal of Tocantins, in Palmas city of Tocantins State. At each period, populations were conducted under high and low $\mathrm{N}$ (150 kg ha-1 N and 0 kg ha-1 N) respectively in the coverage. The experimental design used in each trial was randomized blocks with three replications and 10 treatments. We studied the characteristic percentage of protein and determined the EUN by populations, using the methodology from Fischer. The genetic diversity was performed by multivariate procedures: Mahalanobis distance and grouping method of Tocher in the study of genetic diversity, each trial representing a distinct variable in the multivariate model. The lower content of protein were obtained under low $\mathrm{N}$ the crop period. The Populations POP 3 and POP 13 were efficiency and promising for protein production.

Keywords: Breeding. Nutrition nitrogen. Protein content. 


\section{INTRODUÇÃO}

O milho é um dos cereais mais cultivados e consumidos no Brasil, uma vez que apresenta inúmeros benefícios sociais, econômicos, nutricionais e agroindustriais. Em relação à conteúdo de proteína do grão milho, apresenta em média 9,5\% (Jesus et al., 2008, Castro et al., 2009), que podem variar com o tipo de grão, fertilidade do solo e condições climáticas.

A produtividade é baixa no Estado do Tocantins, em função das altas temperaturas, do baixo nível tecnológico dos produtores e da insuficiência de sementes melhoradas ou de variedades adaptadas às condições de estresses abióticos (Santos et al., 2010, Cancellier et al., 2011).

O nitrogênio $(\mathrm{N})$ é o nutriente mais exigido pela cultura do milho (Pavianato et al., 2008). O N desempenha importante papel no acúmulo de proteína, aumento do peso da espiga e da produtividade de grãos (Pavianato et al., 2008). Além disso, o N é determinante no peso de cem sementes, peso hectolitro (Cancellier et al., 2011) aumento da produtividade de grãos (Duete et al., 2008).

$\mathrm{Na}$ tentativa de transformar o milho num alimento mais completo nutricionalmente, uma abordagem com exploração dos controles genéticos conhecidos de teores de nutrientes nos grãos de milho, associada ao aumento no aproveitamento de $\mathrm{N}$ pela planta e na sua conversão em proteína, sem prejuízo acentuado no rendimento de grãos, representa um grande desafio a ser alcançado pelo melhoramento genético (Bueno et al., 2009).

O desenvolvimento de cultivares adaptados às condições de estresse nitrogenado apresenta-se como uma opção economicamente viável e ecologicamente sustentável. Neste contexto, índices de Eficiência de Uso de Nitrogênio (EUN) vêm sendo utilizados para classificar as populações quanto a essa variável (Cancellier et al., 2011, Carvalho et al., 2011).

Em programas de melhoramento, estudos de divergência genética entre populações milho (Arnhold et al., 2009, Cardoso et al., 2009, Coimbra et al., 2010, Rotili et al., 2012), utilizando caracteres agronômicos, morfológicos e moleculares fornecem informações sobre possíveis combinações híbridas com maior heterozigose, de modo que nas gerações segregantes exista maior probabilidade de sucesso nos cruzamentos (Cruz et al., 2014, Rinaldi et al., 2007, Cargnelutti Filho et al., 2009, Dotto et al., 2010).

Assim, diante da importância econômica que a cultura do milho assume no âmbito tocantinense, a avaliação da diversidade genética de populações e EUN, para a característica de teor de proteína, permitirá identificar as populações mais promissoras e eficientes, o que propõe o presente estudo.

\section{MATERIAL E MÉTODOS}

Foram realizados quatro ensaios de competição de populações de milho no Centro Agrotecnológico da Universidade Federal do Tocantins, Campus de Palmas (220 m de altitude, 1045' de LS e 47이' de LW), em solo do tipo Latossolo Vermelho-Amarelo distrófico, textura arenosa. Os ensaios foram distribuídos em duas épocas de plantio (entressafra e safra), sendo que em cada época, as populações foram cultivadas sob condições de alto (150 kg ha-1 de $\mathrm{N}$ ) e baixo (0 kg ha-1 de N), aplicado em cobertura, tendo como fonte de $\mathrm{N}$ a uréia ( $43 \%$ de $\mathrm{N}$ ).

A semeadura foi realizada em 27 de maio de 2010, para época de entressafra, e 02 de dezembro de 2010, para época de safra 2010/2011. Os dados climatológicos de temperaturas e precipitação encontram-se na Figura 1. 


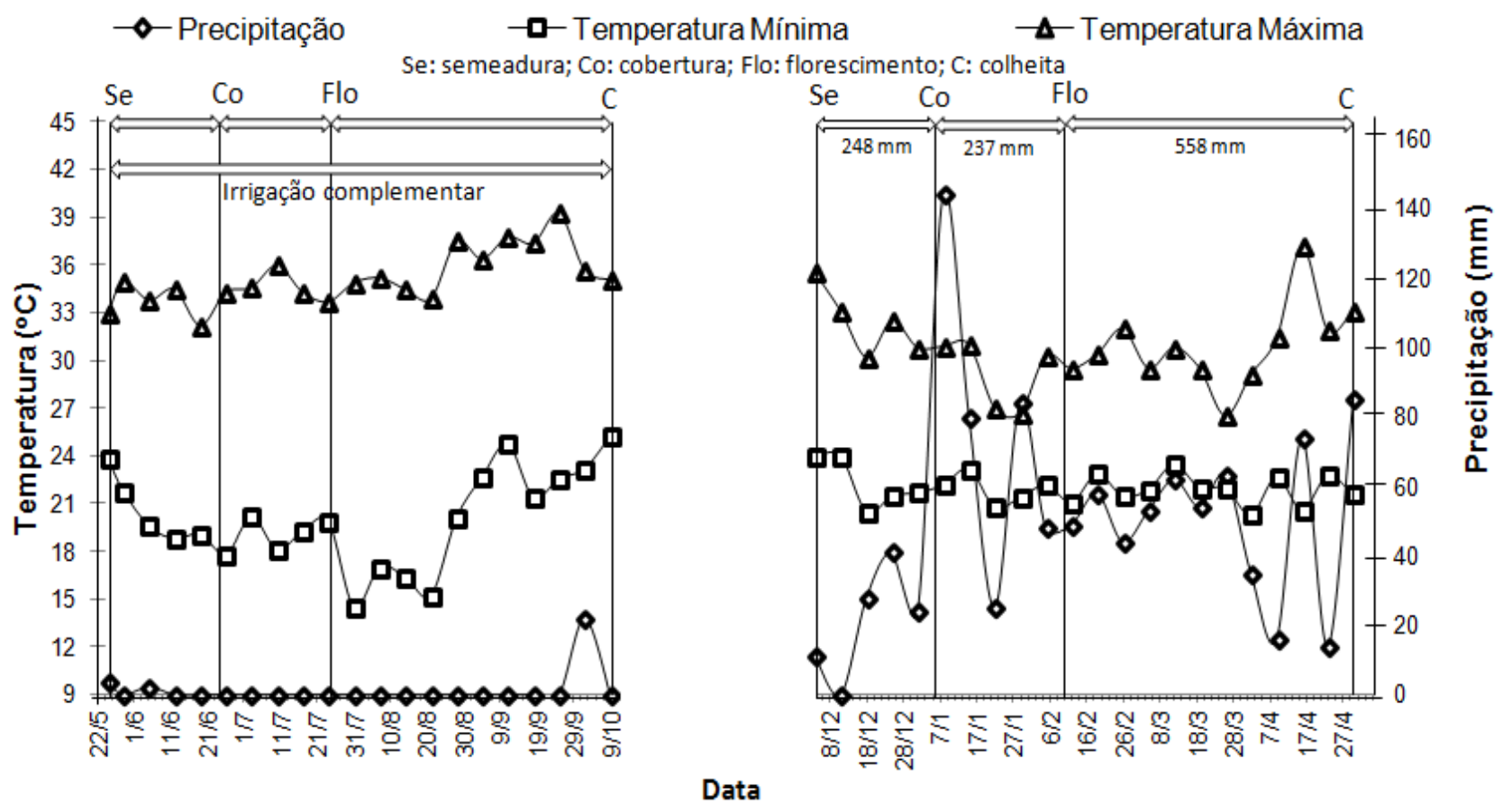

Figura 1. Temperaturas e precipitação pluvial no período de maio de 2010 a abril de 2011, UFT, Palmas-TO.

Figure 1. Temperatures and rainfall in the period from May 2010 to April 2011, UFT, Palmas-TO.

O delineamento experimental utilizado, em cada ensaio, foi blocos casualizados com 10 tratamentos e três repetições. Os tratamentos foram constituídos de 10 populações do Programa de Melhoramento de Milho da UFT, sendo denominadas: POP 3 , POP 8, POP 9, POP 11, POP 12, POP 13, POP 14, POP 16, POP 18, e POP 19.

A parcela experimental foi representada por quatro linhas de cinco metros lineares, espaçadas $0,9 \mathrm{~m}$ entre linhas. Na colheita, foram utilizadas as duas linhas centrais de cada fileira, descartando-se $0,5 \mathrm{~m}$ das extremidades das fileiras.

O sistema de preparo de solo foi o do tipo convencional, com uma gradagem seguida do nivelamento da área. A adubação de pré-plantio foi realizada manualmente, utilizando $300 \mathrm{~kg}$ ha-1 de N-P2O5-K2O de $5-25-15+0,5 \% \mathrm{Zn}$, para todos os ensaios. A semeadura foi realizada com o intuito de se obter 55555 plantas ha-1.

A adubação nitrogenada em cobertura, nos experimentos de safra e entressafra foi de 0 e $150 \mathrm{~kg}$ ha-1, respectivamente, proporcionando totais de 15 e $165 \mathrm{~kg}$ ha-1, para os ambientes de baixo e alto $\mathrm{N}$, sendo realizada no estádio $\mathrm{V} 6$ (seis folhas completamente abertas), tendo como fonte de $\mathrm{N}$ a uréia.

Os tratos culturais, como o controle fitossanitário contra doenças, pragas e plantas daninhas foram realizados de acordo com as recomendações técnicas da cultura (Fancelli \& Dourado Neto, 2000). Foi realizada irrigação suplementar para os ensaios conduzidos na entressafra, sempre que necessário.

As coletas dos dados foram realizadas quando as plantas atingiram o estádio R6 (maturidade fisiológica). Na colheita, com base na área útil da parcela, foi obtida a produtividade de grãos $(\mathrm{kg})$, corrigidos para $13 \%$ de umidade e, posteriormente, convertidos os valores para kg.ha-1.

Nas duas fileiras centrais, de cada parcela experimental, foram colhidas todas as espigas, quando as plantas atingiram o estádio R6 (maturidade fisiológica). Em seguida, as 
espigas foram trilhadas e os grãos acondicionadas em um único saco de papel, o qual foi identificado por população, e realizada a moagem. Após a moagem dos grãos, foi determinado o teor de proteína dos grãos (\%), sendo utilizado o método de Kjeldahl (AOAC, 1995).

Para cada população, foi obtida a EUN, segundo metodologia Fischer et al. (1983), a partir do índice de EUN, obtido pela equação 1:

$$
E U N=Y a(-N) / Y a(+N) \times Y x(-N) / Y x(+N)
$$

Onde:

$\mathrm{Ya}(-\mathrm{N})$ é a produção da população "a" sob baixo nitrogênio, $\mathrm{Ya}(+\mathrm{N})$ é a produção da população "a" sob alto nitrogênio, $Y x(-N)$ é a produção média de todas as populações sob baixo nitrogênio, $e$ $\mathrm{YX}(+\mathrm{N})$ é a produção média de todas as populações sob alto.

Visando estudar a divergência genética apenas para teor de proteína dos grãos, foram utilizados os quatro ensaios como variáveis no modelo multivariado, onde cada ensaio representou uma variável distinta no modelo. As medidas de dissimilaridades foram determinadas segundo o modelo de análise multivariada, o que permitiu a obtenção das matrizes de dissimilaridades e de covariâncias residuais e das médias das populações. Foi aplicado o método de agrupamento de Tocher proposto por Rao (1952), utilizando a distância generalizada de Mahalanobis (D2), como medida de dissimilaridade.

Foi realizada análise de variância (ANOVA) de cada ensaio e, posteriormente a análise conjunta dos ensaios em que o menor quadrado médio residual não diferiu em mais de sete vezes do maior (Cruz et al., 2014). As médias foram comparadas pelo teste de Scott e Knott, ao nível de 5\% de significância.

Os índices de eficiência das populações foram comparados com o índice geral de eficiência pelo teste $t$ de "Student", a 5\% de significância, após teste de normalidade dos dados segundo Kolmogorov-Smirnov. As análises estatísticas foram realizadas utilizando o programa Computacional Genes, versão 2007.

\section{RESULTADOS E DISCUSSÃO}

A análise de variância conjunta (Tabela 1) revelou efeito significativo para populações, ensaios e para a interação populações $x$ ensaios, esta última indicando que os efeitos isolados dos fatores populações e ensaios não explicam toda a variação encontrada, sendo necessária a realização dos desdobramentos. O coeficiente de variação - CV (\%) foi baixo, demonstrando boa precisão experimental na condução dos experimentos.

A análise de variância da EUN pelas populações apresentou efeito significativo entre as populações (Tabela 2), indicando um comportamento diferencial entre as populações quanto à eficiência. Carvalho et al. (2011) avaliando EUN em híbridos de milho, encontrou efeito significativo. 
Tabela 1. Resumo da análise de variância de teor de proteína (\%), de 10 populações de milho

Table 1. Summary of the variance analysis of protein content (\%) of 10 maize populations

\begin{tabular}{lcc}
\hline Fonte de variação & Grau de liberdade & $\begin{array}{c}\text { Quadrado médio } \\
\text { Teor de proteína (\%) }\end{array}$ \\
\hline Bloco/ensaios & 8 & $0,57142^{\text {ns }}$ \\
Populações & 9 & $1,14532^{*}$ \\
Ensaios & 3 & $9,90364^{*}$ \\
Populações x Ensaios & 27 & $2,48852^{*}$ \\
Erro & 72 & 0,48503 \\
\hline Média & - & 11,7 \\
\hline CV \% & - & 5,9 \\
\hline
\end{tabular}

CV: Coeficiente de variação. ns: não significativo, * significativo ao nível de $5 \%$ pelo teste de Scott e Knott.

CV: Coefficient of variation. ns: not significant, ${ }^{*}$ significant at the $5 \%$ level by the Scott and Knott test.

Tabela 2. Resumo da análise de variância da eficiência de uso do nitrogênio, segundo metodologia de Fischer, para teor de proteína (\%), de 10 populações de milho

Table 2. Summary of the analysis of variance of the efficiency of use of nitrogen, according to Fischer's methodology, for protein content (\%), of 10 maize populations.

\begin{tabular}{lcc}
\hline \multicolumn{1}{c}{ Fonte de variação } & Grau de liberdade & $\begin{array}{c}\text { Quadrado médio } \\
\text { Teor de proteína (\%) }\end{array}$ \\
\hline Blocos & 5 & $0,00761^{\text {ns }}$ \\
Populações & 9 & $0,035531^{*}$ \\
Erro & 45 & 0,008433 \\
Média & - & 0,92 \\
CV (\%) & - & 9,9 \\
\hline
\end{tabular}

CV: Coeficiente de variação. ns: Não significativo, * Significativo ao nível de $5 \%$ pelo teste de Scott e Knott.

CV: Coefficient of variation. ns: Not significant, * Significant at the $5 \%$ level by the Scott and Knott test.

As médias de teor de proteína das populações, nos ensaios de alto e baixo $\mathrm{N}$, para épocas da entressafra 2010 e safra 2010/11, encontram-se na Tabela 3. Os teores de proteína, nos grãos de milho das populações variaram de 9,5\% (POP 13) a 14,3\% (POP 18). Esses resultados se assemelham aos encontrados por (Jesus et al., 2008, Castro et al., 2009).

Tabela 3. Médias de teor de proteína P (\%), em 10 populações de milho, nas épocas de safra 2010/11 e entressafra 2010, nos ensaios em alto e baixo N e índice de Fischer

Table 3. Averages of protein P content (\%) in 10 maize populations, in seasons 2010/11 and crop 2010, essay in the tall and low $\mathrm{N}$ and Fischer index

\begin{tabular}{ccccccccc}
\hline \multirow{2}{*}{ População } & \multicolumn{2}{c}{ Entressafra 2010} & \multicolumn{2}{c}{ Safra $2010 / 2011$} & \multirow{2}{*}{ Média } & Índice & (\%) \\
\cline { 2 - 4 } & Baixo & Alto & Baixo & Alto & & & \\
\hline POP 3 & $12,7 \mathrm{Aa}$ & $12,1 \mathrm{Aa}$ & $11,2 \mathrm{Ba}$ & $12,4 \mathrm{Ab}$ & $12,1 \mathrm{a}$ & $0,94 \mathrm{a}$ & 102,2 \\
POP 8 & $12,2 \mathrm{Aa}$ & $12,8 \mathrm{Aa}$ & $11,5 \mathrm{Ba}$ & $10,8 \mathrm{Bc}$ & $11,8 \mathrm{a}$ & $0,97 \mathrm{a}$ & 105,4 \\
POP 9 & $12,3 \mathrm{Aa}$ & $12,6 \mathrm{Aa}$ & $10,9 \mathrm{Bb}$ & $12,3 \mathrm{Ab}$ & $12,0 \mathrm{a}$ & $0,89 \mathrm{~b}$ & 96,7 \\
POP 11 & $12,1 \mathrm{Aa}$ & $12,0 \mathrm{Aa}$ & $11,6 \mathrm{Aa}$ & $11,0 \mathrm{Ac}$ & $11,7 \mathrm{a}$ & $0,99 \mathrm{a}$ & 107,6 \\
POP 12 & $12,3 \mathrm{Aa}$ & $12,4 \mathrm{Aa}$ & $10,4 \mathrm{Bb}$ & $11,9 \mathrm{Ab}$ & $11,8 \mathrm{a}$ & $0,90 \mathrm{~b}$ & 97,8 \\
\hline
\end{tabular}

"Continua" 
Continuação tabela 3

\begin{tabular}{|c|c|c|c|c|c|c|c|}
\hline \multirow{2}{*}{ População } & \multicolumn{2}{|c|}{ Entressafra 2010} & \multicolumn{2}{|c|}{ Safra 2010/2011 } & \multirow{2}{*}{ Média } & \multirow{2}{*}{ Índice } & \multirow{2}{*}{ (\%) } \\
\hline & Baixo & Alto & Baixo & Alto & & & \\
\hline POP 13 & $12,7 \mathrm{Aa}$ & $12,6 \mathrm{Aa}$ & $11,3 \mathrm{Ba}$ & $9,5 \mathrm{Cd}$ & $11,5 \mathrm{a}$ & $1,05 a^{*}$ & 114,1 \\
\hline POP 14 & $11,1 \mathrm{Bb}$ & $12,0 \mathrm{Aa}$ & $10,4 \mathrm{Bb}$ & $10,6 \mathrm{Bc}$ & $11,0 \mathrm{a}$ & $0,93 \mathrm{a}$ & 100,0 \\
\hline POP 16 & $11,6 \mathrm{Ab}$ & $12,4 \mathrm{Aa}$ & $11,9 \mathrm{Aa}$ & $11,3 \mathrm{Ac}$ & $11,8 \mathrm{a}$ & $0,96 a$ & 104,3 \\
\hline POP 18 & $10,5 \mathrm{Bb}$ & $11,4 \mathrm{Ba}$ & $10,4 \mathrm{Bb}$ & $14,3 \mathrm{Aa}$ & $11,7 \mathrm{a}$ & $0,79 \mathrm{~b}$ & 85,9 \\
\hline POP 19 & $12,0 \mathrm{Aa}$ & $13,3 \mathrm{Aa}$ & $10,3 \mathrm{Bb}$ & $12,5 \mathrm{Ab}$ & $12,0 \mathrm{a}$ & $0,83 \mathrm{~b}$ & 90,2 \\
\hline Média & $11,9 \mathrm{~A}$ & $12,4 \mathrm{~A}$ & $11,0 \mathrm{~A}$ & $11,6 \mathrm{~A}$ & 11,7 & 0,92 & 100 \\
\hline
\end{tabular}

POP: População, Médias seguidas por mesma letra maiúscula na linha e minúscula na coluna não diferem entre si, a $5 \%$ pelo teste de Scott e Knott. *Médias estatisticamente diferentes da média geral, pelo teste t, a $5 \%$.

POP: Population, Averages followed by the same capital letter in the row and lowercase in the column do not differ from each other, to $5 \%$ by the Scott and Knott test. * Averages statistically different from the general mean by the $t$ test at $5 \%$.

Na entressafra 2010, com exceção da população POP 14, as demais populações apresentaram similaridade de comportamento sob alto e baixo $\mathrm{N}$ (Tabela 3). No ensaio de alto $\mathrm{N}$, não foram detectadas diferenças significativas entre as populações. Por outro lado, sob baixo $\mathrm{N}$, as populações foram separadas em dois grupos de médias, sendo o grupo com o maior conteúdo proteico representado por $70 \%$ das populações e o de menor conteúdo pelas populações POP 14, POP 16 e POP 18.

$\mathrm{Na}$ época da safra 2010/11, as populações apresentaram, de modo geral, comportamento diferencial quando comparados os ensaios de baixo e alto $\mathrm{N}$ (Tabela 3). Enquanto, as populações POP 11 e POP 16 apresentaram comportamento similar em ambos os ensaios, as demais populações revelaram maior conteúdo proteico sob alto $\mathrm{N}$. Nesta época, sob alto $\mathrm{N}$, as populações foram distribuídas em quatro grupos de médias, onde as POP 18 e POP 13 apresentaram, respectivamente, a maior e menor teor de proteína nos grãos. Sob baixo $\mathrm{N}$, foram formados dois grupos de médias. No grupo com as maiores médias encontram-se as POP 3, POP 8, POP 11, POP 13 e POP 16 e com as menores médias POP 9, POP 12, POP 14, POP 18 e POP 19.

O estudo comparativo entre as épocas de semeaduras, para cada população, revelou um comportamento similar para as POP 11 e POP 16 (Tabela 3). Para as populações POP 3, POP 9, POP 12 e POP 19, foi observado um menor teor de proteína nos ensaios de safra 2010/11 em baixo N. Por outro lado, as populações POP 8 e POP 13 apresentaram um maior teor de proteína na entressafra 2010, em relação aos ensaios de safra 2010/11, independentemente dos níveis de N. A população $P$ 18, por sua vez, apresentou a maior média protéica sob alto N na safra 2010/11.

De modo geral observou-se uma tendência de maior teor protéico nos grãos quando as populações foram cultivadas sob alto $\mathrm{N}$, independentemente da época de semeadura. Esses resultados estão em concordância com aquele obtido por Farinelli e Lemos (2012) que também encontraram efeitos significativos no incremento de proteína nos grãos de milho em função de aumento nos níveis de adubação nitrogenada. Por outro lado, Oliveira et al. (2012) verificou que os teores de proteína não foram influenciados pelos níveis de adubação nitrogenada. 
Segundo Castro et al. (2009) diferentes níveis de adubação nitrogenada influenciam na produtividade e no teor de proteína do grão uma vez que o $\mathrm{N}$ exerce importante função nos processos bioquímicos da planta, como constituinte de proteínas, enzimas, coenzimas, ácidos nucleicos, fitocromos e clorofila.

Os menores valores de proteína nos grãos, nas populações cultivadas sob baixo nível de $\mathrm{N}$ na safra, quando comparados aos obtidos sob baixo $\mathrm{N}$ na entressafra 2011 ocorreram, provavelmente, em virtude de irregularidades na distribuição de chuvas e presença de temperaturas noturnas mais altas na época de safra (Figura 1), que resultaram em efeitos adversos na quantidade e na qualidade dos grãos.

Segundo Oliveira et al. (2012), deficiências hídricas no período do florescimento, resultam em queda no número de óvulos formados e, consequentemente, no número de grãos. Além disto, as temperaturas elevadas prevalecentes no período noturno $\left(>24^{\circ} \mathrm{C}\right)$ promovem um consumo energético elevado, em função do incremento da atividade respiratória, ocasionando em queda no fornecimento de assimilados, com consequente queda no rendimento da cultura (Fancelli \& Dourado Neto, 2000).

Em relação à eficiência e uso do $\mathrm{N}$ (EUN), as populações foram divididas em dois grupos, para o teor de proteína nos grãos (Tabela 3 ). 0 grupo com as maiores médias de eficiência foi composto por seis populações, quais sejam: POP $13(1,05)$, POP $11(0,99)$, POP $8(0,97)$, POP $16(0,96)$, POP $3(0,94)$ e POP $14(0,93)$, onde apenas POP 13 se diferiu significativamente da média geral $(0,92)$.

O grupo com as menores médias de eficiência para teor de proteínas (Tabela 3), inclusive abaixo da média geral de eficiência $(0,92)$, foi composto por POP $12(0,90)$, POP $9(0,89)$, POP $19(0,83)$ e POP $18(0,79)$.

As medidas de dissimilaridade genética, estimadas a partir da distância de Mahalanobis (Tabela 4), para a característica teor de proteína, apresentaram uma elevada magnitude $(0,64$ a 152,52$)$.

Tabela 4. Dissimilaridade entre populações de milho em relação a características teor de proteína, nas épocas de safra 2010/11 e entressafra 2010, nos ensaios em alto e baixo $\mathrm{N}$

Table 4. Dissimilarity among maize populations in relation to protein content in the $2010 / 11$ harvest season and 2010 off season, in the high and low $\mathrm{N}$ trials

\begin{tabular}{llllllllll}
\hline População & POP 8 & POP 9 & POP 11 & POP 12 & POP 13 & POP 14 & POP 16 & POP 18 & POP 19 \\
\hline POP 3 & 26,16 & 0,64 & 22,99 & 2,62 & 61,21 & 31,65 & 26,76 & 25,54 & 4,52 \\
POP 8 & & 24,22 & 1,00 & 24,26 & 9,58 & 7,73 & 1,73 & 92,55 & 37,77 \\
POP 9 & & & 22,16 & 1,91 & 59,19 & 29,06 & 24,94 & 25,52 & 2,52 \\
POP 11 & & & & 21,27 & 10,98 & 5,80 & 2,15 & 85,26 & 36,19 \\
POP 12 & & & & 53,84 & 22,63 & 27,44 & 29,11 & 3,75 \\
POP 13 & & & & & 12,63 & 15,48 & 152,52 & 77,91 \\
POP 14 & & & & & & 11,18 & 87,95 & 39,36 \\
POP 16 & & & & & & & 87,50 & 39,31 \\
POP 18 & & & & & & & & & 18,19
\end{tabular}

POP: População.

POP: Population. 
A combinação entre POP 13 e POP 18 foi a mais divergente $\left(D^{2}=152,52\right)$, seguida pelas combinações POP 8 e POP $18\left(D^{2}=92,55\right)$ e os pares POP 14 e POP $18\left(D^{2}=87,85\right)$ e POP 16 e POP $18\left(D^{2}=87,50\right)$ (Tabela 4). A menor distância foi obtida entre as populações POP 3 e POP $9\left(D^{2}=0,64\right)$, seguido pelos pares POP 8 e POP $11\left(D^{2}=1,00\right)$ e POP 8 e POP $16\left(D^{2}=1,73\right)$. Ressalta-se que entre as maiores distâncias encontradas, a população POP 18 está presente na grande maioria das combinações.

A análise da distância genética pode auxiliar na escolha dos genitores para futuros cruzamentos, possibilitando economia de tempo, mão-de-obra e recursos financeiros em futuros estudos (Cruz, et al., 2014, Cargnelutti Filho et al., 2009). Contudo, apesar das distâncias terem alta representatividade, as análises de agrupamento tornam-se fundamentais para a escolha dos progenitores, pois os novos híbridos a serem estabelecidos devem ser baseados nas dissimilaridades observadas (Rotili et al., 2012),

A análise de agrupamento pelo Método de Tocher resultou na formação de três grupos (Tabela 5). O grupo I foi representado por quatro populações (POP 3, POP 9, POP 12 e POP 19), o grupo II por cinco populações (POP 8, POP 11, POP 16, POP 14 e POP 13) e o grupo III apenas pela população POP 18. Segundo Cruz et al. (2014) grupos formados por apenas um indivíduo apontam na direção de que tais indivíduos sejam mais divergentes em relação aos demais.

Tabela 5. Agrupamento pelo método de Tocher, de 10 populações de milho, para teor de proteína, nas épocas de safra 2010/11 e entressafra 2010, nos ensaios em alto e baixo N

Table 5. Grouping by Tocher's method of 10 maize populations for protein content in the 2010/11 harvest season and 2010 off season in the high and low $N$ trials

\begin{tabular}{ccc}
\hline Grupos & Populações & \% de amostras \\
\hline I & POP 3, POP 9, POP 12 e POP 19 & 40 \\
II & POP 8, POP 11, POP 16, POP 14 & 50 \\
III & e POP 13 & 10 \\
\hline Total & POP 18 & 100 \\
\hline
\end{tabular}

POP: População.

POP: Population.

A análise de agrupamento estabelecida pelo método de Tocher (Tabela 5), juntamente com a análise de comparação das médias e EUN (Tabela 3), permite inferir que as populações POP 3 e POP 13 poderão ser utilizadas como progenitores em futuros programas de melhoramento, visando o desenvolvimento de genótipos para as condições onde o nível tecnológico empregado seja baixo.

\section{CONCLUSÃO}

O menor conteúdo de proteína nos grãos foi obtido sob baixo $\mathrm{N}$ na safra.

As populações POP 3 e POP 13 são promissoras para produção de proteínas e EUN.

\section{CONTRIBUIÇÃO DOS AUTORES}

Elaboração do manuscrito, revisão de literatura, condução do experimento e análises estatísticas: Autores WFS e LFS, Revisão final do artigo: Autor FSA, JMP, ER e JSP. 


\section{CONFLITO DE INTERESSE}

Os autores declararam que não há conflito de interesse.

\section{FINANCIAMENTO}

Os autores declararam que não houve financiamento para o desenvolvimento da pesquisa

\section{REFERÊNCIAS}

AOAC-Association of Official Analytical Chemists (1995). Official Methods of Analysis. (16a ed.) Arlington: AOAC, v.2.

Arnhold, E., Viana, J. M. S., \& Silva, R. G. (2009). Associação de desempenho entre famílias S3 e seus híbridos topcross de milho-pipoca. Revista Ciência Agronômica, 40(3), 396-399.

Bueno, L. G., Chaves, L. J., Oliveira, J. P., Brasil, E. M., Reis, A. J. S., Assunção, A., Pereira, A. F., \& Ramos, M. R. (2009) Controle genético do teor proteico nos grãos e de caracteres agronômicos em milho cultivado com diferentes níveis de adubação nitrogenada. Pesquisa Agropecuária Brasileira, 44(6), 590-598, 2009. https://doi.org/10.1590/S0100-204X2009000600007

Cancellier, L. L., Afférri, F. S., Carvalho, E. V., Dotto, M. A., \& Leão, F. F. (2011). Eficiência no uso de nitrogênio e correlação fenotípica em populações tropicais de milho no Tocantins. Revista Ciência Agronômica, 42(1), 139-148. https://doi.org/10.1590/S1806-66902011000100018

Cardoso, W. S., Paes, M. C. D., Galvão, J. C. C., Rios, S. A., Guimarães, P. E. O., Schaffert, R. E., \& Borém, A. (2009). Variabilidade de genótipos de milho quanto à composição de carotenóides nos grãos. Pesquisa Agropecuária Brasileira, 44(2), 164-173. https://doi.org/10.1590/S0100-204X2009000200008

Cargnelutti Filho, A., Ribeiro, N. D., \& Jost, E. (2009). Número necessário de experimentos para a análise de agrupamento de cultivares de feijão. Ciência Rural, 39(2), 371-378. https://doi.org/10.1590/S010384782008005000059

Carvalho, E. V., Afférri, F. S., Peluzio, J. M., Leão, F. F., Cancellier, L.L., \& Dotto, M. A. (2011). Eficiência e uso do nitrogênio em híbridos experimentais de milho do programa de melhoramento da Universidade Federal do Tocantins. Bioscience Journal, 27(3), 392-403.

Castro, M. V. L., Naves, M. M. V., Oliveira, J. P., \& Froes, L. O. (2009). Rendimento industrial e composição química de milho de alta qualidade proteica em relação a híbridos comerciais. Pesquisa Agropecuária Tropical, 39(3), 233-242.

Coimbra, R. R., Miranda, G. V., Cruz, S. D., Melo, A. V. M., \& Eckert, F. R. (2010). Caracterização e divergência genética de populações de milho resgatadas do Sudeste de Minas Gerais. Revista Ciência Agronômica, 41(1), 159-166.

Cruz, C. D., Regazzi, A. J., \& Carneiro, P. C. S. (2014). Modelos biométricos aplicados ao melhoramento genético. (3a ed.) Viçosa: UFV, 668p.

Dotto, M. A., Afférri, F. S., Peluzio, J. M., Melo, A. V., \& Carvalho, E. V. (2010). Divergência genética entre cultivares comerciais de milho em baixas altitudes no Tocantins, safra 2007/2008. Revista Ciência Agronômica, 41(4), 630-637. https://doi.org/10.1590/\$1806-66902010000400017 
Duete, R. R. C., Muraoka, T., Silva, E. C., Trivelin, P. C. O., \& Ambrosano, E. J. (2008). Manejo da adubação nitrogenada e utilização do nitrogênio (15N) pelo milho em Latossolo Vermelho. Revista Brasileira de Ciência do Solo, 32(1), 161-171. https://doi.org/10.1590/S0100-06832008000100016

Fancelli, A. L., \& Dourado-Neto, D. (2000). Produção de milho. Guaíba: Agropecuária, 360 p.

Farinelli, R., \& Lemos, L. B. (2012). Nitrogênio em cobertura na cultura do milho em preparo convencional e plantio direto consolidados. Pesquisa Agropecuária Tropical, 42(1), 63-70. https://doi.org/10.1590/S198340632012000100009

Fischer, K. S., Johnson, E. C., \& Edmeads, G. O. (1983). Breeding and selection for drought in tropical maize. México: CIMMYT.

Jesus, W. C., Brasil, E. M., Oliveira, J. P., Pinto, G. R. C., Chaves, L. J., \& Ramos, M. R. (2008). Heterose para teor de proteína no grão em cruzamentos entre populações de milho derivadas de híbridos comerciais. Pesquisa Agropecuária Tropical, 38(1), 32-38.

Oliveira, M. A., Zucareli, C., Spolaor, L. T., Domingues, A. R., \& Ferreira, A. S. (2012). Composição química dos grãos de milho em resposta à adubação mineral e inoculação com rizobactérias. Revista Ceres, 59(5), 709715. https://doi.org/10.1590/S0034-737X2012000500018

Paterniani, M. A. G. Z., Guimarães, P. S., Lüders, R. R., Laborda, P. R., Gallo, P. B., Oliveira, K. M., \& Souza, A. P. (2008). Capacidade combinatória, divergência genética entre linhagens de milho e correlação com heterose. Bragantia, 67(3), 639-648. https://doi.org/10.1590/S0006-87052008000300012

Pavinato, P. S., Ceretta, C. A., Girotto, E., \& Moreira, I. C. L. (2008). Nitrogênio e potássio em milho irrigado: análise técnica e econômica da fertilização. Ciência Rural, 38(2), 358-364. https://doi.org/10.1590/S010384782008000200010

Rao, C. R. (1952). Advanced statistical methods in biometric research. New York: John Willey, 390p.

Rinaldi, D. A., Pípolo, V. C., Gerage, A. C., Ruas, C. F., Fonseca, N. S., Souza, A., Sousa, S. G. H., \& Garbuglio, D. D. (2007). Correlação entre heterose e divergência genética estimadas por cruzamentos dialélicos e marcadores moleculares RAPD em populações de milho-pipoca. Bragantia, 66(2), 183-192. https://doi.org/10.1590/S0006-87052007000200002

Rotili, E. A., Cancellier, L. L., Dotto, M. A., Peluzio, J. M., \& Carvalho, E. V. (2012). Divergência genética em genótipos de milho, no estado do Tocantins. Revista Ciência Agronômica, 43(3), 516-521. https://doi.org/10.1590/S1806-66902012000300014

Santos, M. M., Galvão, J. C. C., Silva, I. R., Miranda, G. V., Finger, F. L. (2010). Épocas de aplicação de nitrogênio em cobertura na cultura do milho em plantio direto, e alocação do nitrogênio (15N) na planta. Revista Brasileira Ciência do Solo, 34(4), 1185-1194. https://doi.org/10.1590/\$0100-06832010000400018 